\title{
COMPREENDENDO A NOÇÃO DE EXPERIÊNCIA CORPORAL EM MERLEAU-PONTY: CONTRIBUIÇÕES PARA A EDUCAÇÃ̃o
}

\author{
Mauricio Bueno da $\operatorname{Rosa}^{\mathbf{1}}$ \\ Faculdade de Tecnologia e Ciências do Norte do Paraná (FATECIE) \\ https://orcid.org/0000-0003-1407-357X \\ E-mail: mauriciobueno7@hotmail.com
}

\section{RESUMO:}

A partir da fenomenologia de Merleau-Ponty podemos perceber que o ponto de vista da corporeidade se relaciona diretamente com o desafio da educação, o corpo não é tomado como um objeto no espaço e no tempo, ou então em movimento, definido exclusivamente como um conjunto de partes. A relação entre filosofia e arte se faz fundamental para pensar a formação humana e a educação nos termos que estamos pesquisando aqui, pois trata-se da própria fundamentação do conhecimento, a partir de uma atitude de experiência perceptiva com o mundo no qual estamos inseridos. Com isso, neste artigo demonstraremos que a arte se aproxima da filosofia e da educação, pois é impossível filosofar renegando a condição humana, posto que essa ação pretende desvelar o sentido original do ser. Portanto, ao invés de negá-la, é necessário assumi-la. Ao final, debruçados nas pesquisas de Merleau-Ponty, poderemos compreender a árdua tarefa que é defrontar o mistério da sensibilidade na esfera da educação, admitir a arte enquanto tarefa infinita e a filosofia como uma reflexão inacabada, além de identificar as ambiguidades e contradições que permeiam nossas vidas.

PALAVRAS-CHAVE: Merleau-Ponty; Fenomenologia; Percepção; Educação; Arte.

\section{UNDERSTANDING THE NOTION OF BODY EXPERIENCE IN MERLEAU-PONTY: CONTRIBUTIONS TO EDUCATION}

\begin{abstract}
:
From Merleau-Ponty's phenomenology we can see that the point of view of corporeality is directly related to the challenge of education, the body is not taken as an object in space and time, or in motion, defined exclusively as $\mathrm{A}$ set of parts. The relationship between philosophy and art is fundamental to think human formation and education in the terms we are researching here, because it is the very foundation of knowledge, from an attitude of perceptive experience with the world in which we are inserted. Thus, in this article we will demonstrate that art is close to philosophy and education, since it is impossible to philosophize by denying the human condition, since this action intends to unveil the original meaning of being. Therefore, instead of denying it, it is necessary to assume it. Finally, looking at Merleau-Ponty's research, we can understand the arduous task of confronting the mystery of sensibility in the sphere of education, admitting art as an infinite task and philosophy as an unfinished reflection, and identifying the ambiguities and contradictions that permeate our lives.
\end{abstract}

KEYWORDS: Merleau-Ponty; Phenomenology; Perception; Education; Art.

\footnotetext{
${ }^{1}$ Doutor pela Universidade Federal de Santa Catarina (UFSC), Florianópolis - SC, Brasil. Colaborador da Faculdade de
} Tecnologia e Ciências do Norte do Paraná (FATECIE), Paranavaí - PR, Brasil.

ROSA, Mauricio Bueno da. Compreendendo a noção de experiência corporal em Merleau-Ponty: contribuições para a educação. Griot : Revista de Filosofia, Amargosa-BA, v.20, n.2, p.347-359, junho, 2020. 


\section{Introdução}

Pretendemos com este artigo apontar algumas possibilidades de fundamentação de uma concepção de educação mediante a noção de logos estético, pois esta concepção possibilita vivenciarmos e percebermos o mundo de forma sensível e direta. Esta parece-nos ser uma forma de conhecimento que deve ser levada em conta no processo de aprendizagem. Defendemos que, a partir do que Merleau-Ponty compreende como infância, podemos compreender a experiência sensível do corpo com o mundo, uma experiência marcada pela ingenuidade e destituída de uma finalidade de racionalização.

A expressão corporal e a significação são complementares e essenciais na vida do homem. No pensamento de Merleau-Ponty, em razão da relação que faz entre arte e corpo-próprio, tanto a expressão corporal como a significação ultrapassam suas próprias dimensões. $O$ corpo será tratado aqui como núcleo significativo que tem na criação artística sua semelhança mais completa, no que diz respeito à expressividade e à originalidade.

Sabe-se que a teoria fenomenológica de Merleau-Ponty não tem como pretensão conceber um sistema ${ }^{2}$ fechado, isto é, ideias estáticas, mas preza a permanente busca filosófica, direcionada para uma viva ebulição de ideias, sem que haja cristalizações ou estagnações que encurralam o nosso pensamento. ${ }^{3}$

O corpo-sujeito forma uma ambiguidade que nos leva a pensar não na junção entre sujeito e corpo, mas para além. A noção de corpo-sujeito ou sujeito-corpo ultrapassa e supera o dualismo entre corpo e consciência. ${ }^{4}$

\section{Corpo e percepção}

Merleau-Ponty pretendeu a recuperação do ser, não em nós ou fora de nós, mas num ponto em que os dois movimentos se encontram, onde "existe" algo. Com isso, entende-se que o filósofo não deve buscar certezas absolutas, uma vez que a prática filosófica "é o movimento que leva incessantemente do saber à ignorância, da ignorância ao saber." (PhP, p. 11). Não se pode exercer a reflexão em abandono da condição no mundo, é preciso acolhê-la. $O$ conhecimento filosófico está na percepção.

Em Merleau-Ponty, há uma concepção de corpo que pode ser entendida a partir da expressão de sentido, constituindo-se numa forma de encontro do homem com o mundo natural, por meio de intenções corporais; por isso estamos no mundo, estamos condenados ao sentido, e não podemos fazer nada nem dizer nada que não adquire um nome na história.

A partir disso, podemos avançar na interpretação que vê na noção de corpo-próprio um direcionamento ininterrupto com o mundo natural, mediante a qual promove a sua transformação e, assumindo outras perspectivas e encontrando diferentes sentidos, desvenda suas diversas facetas. $O$ corpo consiste em um "valer-se" do mundo de forma imediata e pré-

\footnotetext{
${ }^{2}$ Merleau-Ponty nunca teve a intenção de construir um sistema: manteve durante toda sua obra a certeza de que a filosofia deve ser uma interrogação constante, um pensar sempre em movimento, sem meta final, um verdadeiro exercício de uma "dialética sem síntese." (COELHO; CARMO, 1991, p. 14)

${ }^{3}$ A filosofia de Merleau-Ponty é então, um saber impregnado de não saber. O saber nunca é acabado, porque o que pode ser conhecido nunca fica acabado.

${ }_{4}$ Não há busca de uma nova síntese que conciliasse os opostos definitivamente, mas sim a certeza de que é na dinâmica entre polaridades que pode ser encontrado o fundamento para um pensar que consiste, acima de tudo, em saber circunscrever um campo a ser pensado. (COELHO; CARMO, 1991, p. 16)
}

ROSA, Mauricio Bueno da. Compreendendo a noção de experiência corporal em Merleau-Ponty: contribuições para a educação. Griot : Revista de Filosofia, Amargosa - BA, v.20, n.2, p.347-359, junho, 2020. 
reflexiva. Na organização corporal, há atos significativos de natureza prática, não universalizados nunca, pois que se conservam abertos para significações perceptivas novas.

Merleau-Ponty entende que a filosofia está sempre por ser feita, de modo que as suas suposições teóricas não são um sistema íntegro e acabado, uma vez que existe o pré-reflexivo demandando questionamento.

O meu corpo realiza a minha existência: é a minha possibilidade geral de habitar todos os ambientes do mundo. É a base da minha existência como "Eu". O corpo nunca é totalmente transparente para nós. Mesmo em nossos atos mais reflexionados, há algo de anônimo, algo que ainda não é justificado. Nunca estou presente totalmente para mim mesmo; sempre me misturo com meu corpo que "sabe" mais do mundo e de mim mesmo. (PhP, p. 27)

Na concepção merleaupontyana do corpo, a categoria fundamental é a intencionalidade. Para o filósofo, a ciência carecia de levar em consideração a experiência vivenciada e intencional, existente no campo perceptivo, que, de acordo com a estrutura do corpo-próprio, possibilita o nosso entrelaçamento com a realidade sensível. Merleau-Ponty não fala de consciência intencional, conforme a acepção husserliana, que distingue o "sujeito transcendental do sujeito encarnado e situado no espaço e no tempo. Todo objeto intencional remete à consciência transcendental, fonte pura de significações que constituem o mundo e o eu empírico" (PhP, p. 159). A intencionalidade, no pensamento merleaupontyano, é aquilo que possibilita ao autor o reconhecimento do sujeito enquanto ser no mundo, uma vez que significa o retorno ao irrefletido, isto é, ao mundo vivido, a uma realidade que antecede a reflexão e sobre a qual é construída a ciência. $O$ pensamento fenomenológico concebe a intencionalidade como abertura para o mundo externo; assim, ela deixa de ser uma peculiaridade da consciência e passa a ser um aspecto do corpo situado no mundo e para ele direcionado.

Desse ponto de vista, a intencionalidade se apresenta como pré-consciente, o que não contradiz o fato de ser também consciente. Não se trata de uma consciência resultante da inconsciência ou do vazio, mas de uma consciência corporal, existente já na gênese do nosso pensar. Por meio da intencionalidade, em razão da condição ser-no-mundo, o sujeito se relaciona com os objetos de maneira mais aproximada, já que, conforme foi exposto, as nossas relações progridem perceptivamente para com o mundo sensível a partir dessa condição.

Para Merleau-Ponty, o sujeito é transcendental, uma vez que é um sujeito-corpo situado e indissociável do mundo. O filósofo não nos fala de um sujeito de consciência transcendental, seu pensamento não admite um sujeito espiritual como esse. O filósofo, para ele, deve valorizar um eu perceptivo e não buscar um ideal de racionalidade.

O único modo de experienciar o pensamento vivo é por intermédio do corpo, que, conforme o campo perceptivo, busca constantemente estabelecer uma relação com o mundo préobjetivo. Pode-se dizer, então, que o ato de significação está associado às situações vivenciadas e, a partir disso, nosso corpo nos faz assumir uma imposição de sentido, que não advém de uma consciência constituinte universal, visto que o corpo é uma fonte de significação. "Nele aprendemos a conhecer esse nó entre a essência e a existência que em geral reencontramos na percepção" (PhP, p. 203-204). Logo, o pensamento explícito antecede o ato significativo, que nasce e se desenvolve de acordo com a nossa existência perceptiva, completamente ligada ao mundo vivido: 
mais plena edificação. Com a Lebenswelt quer se chegar àquele mundo que antecede ao pensamento crítico e abstrato, assim, podemos ressaltar que na fenomenologia merleaupontyana é esta fundamentação de mundo que mais está presente, um mundo vivenciado, que está interligado com um sujeito-corpo, o qual está enredado no mundo e é por isso, que é no mundo que ele se conhece [...] a o mundo passa a ser denominado como aquilo que eu vivo. ( $\mathrm{PhP}$, p. 14)

O sentido, para Merleau-Ponty, não é obtido apenas com processos inteligíveis; há nas vivências um sentido originário oculto ${ }^{5}$, que o logos estético é capaz de conhecer. A respeito disso, o filósofo diz o seguinte:

Um romance, um poema, um quadro, uma peça musical são indivíduos, quer dizer, seres em que não se pode distinguir a expressão do expresso, cujo sentido só é acessível por um contato direto, e que irradiam sua significação sem abandonar seu lugar temporal e especial. É nesse sentido que nosso corpo é comparável à obra de arte. Ele é um nó de significações vivas e não a lei de um certo número de termos covariantes. ( $\mathrm{PhP}, 209-210)$

A expressão é incapaz de se desprender do exprimido, formando, consequentemente, uma unidade corporal. O significado e o signo, portanto, são aglutinados pelo corpo. É com base nessa ideia que a relação entre obra de arte e corpo pode ser pensada.

O olhar conquista uma relevância impar com a experiência do corpo-próprio, dado que é capaz de tirar das coisas a possibilidade ou o exercício da competência expressiva realizada em uma obra artística. Utilizando a pintura, Merleau-Ponty mostra a relação que esta mantém com o mundo, voltando-se para ele sempre com um espírito questionador. $O$ artista pinta a sua forma de ver o mundo com base na magia do olhar, o olho "é aquilo que foi comovido por um certo impacto do mundo, e que o restitui ao visível pelos traços da mão." (C, p. 43). Em MerleauPonty, o corpo-próprio recebe uma nova acepção, cujo significado passa a estar ligado à existência do homem. Fazendo uma correlação com o fazer estético, o corpo é um núcleo de sentido que encontra na arte a mais completa realização da expressão perceptiva.

A noção de experiência, de acordo com Merleau-Ponty, deve ser assimilada por meio da arte integralmente, nunca fragmentada. Tendo isso em vista, buscamos neste trabalho, a partir das reflexões aqui feitas, tornar mais clara a condição da arte no âmbito da fenomenologia merleaupontyana, assim como a relação com o conhecimento e com a educação.

A ideia de corpo-próprio proposta por Merleau-Ponty é responsável por fazer sobressair o corpo dentre as coisas do mundo, de modo a caracterizar os sentidos e fazendo com que o homem, situado em um mundo, passe a ser visto como sujeito imbuído de intenções. Dessa forma, o progresso no pensamento filosófico está na acepção de que o corpo-próprio deve ultrapassar a mera objetivação, sendo este um ponto de vista da experiência que possibilita a instauração de relações de sentido.

Uma pedagogia que se fundamenta na corporeidade não verá os corpos como objetos, assim como não aplicará conteúdos escolares materializados em filmes, mapas, apostilas ou livros, isto é, em suportes que não foram mediados pelos sentidos corporais dos estudantes e da comunidade de que fazem parte. É válido dizer que os conteúdos mencionados se inserem em um espaço e em um tempo e sofrem permanente inferência corporal por meio dos sentidos, os quais podem renovar seus significados. Nesse caso, a percepção de conteúdos educacionais aparece

\footnotetext{
${ }^{5}$ Esta busca pelo sentido originário, pré-objetivo, se estende até a obra Visível e Invisível, onde o conceito de carne é uma tentativa de fundar a gênese do conhecimento através da dilatação do conceito de corpo-próprio.
}

ROSA, Mauricio Bueno da. Compreendendo a noção de experiência corporal em Merleau-Ponty: contribuições para a educação. Griot : Revista de Filosofia, Amargosa - BA, v.20, n.2, p.347-359, junho, 2020. 
como resultante de diversos olhares e de perspectivas várias, não esgotando, com isso, as muitas possibilidades de atribuição de novos sentidos.

O ponto de vista da corporeidade se relaciona diretamente com o desafio da educação, pois promove a formação de corpos em instituição onde, tanto fora como dentro do estabelecimento, as relações são vistas como criativas perante os conteúdos propostos, sendo eles tomados como uma educação em espaço, de objetivo corporal, que implica o conhecimento e o aprendizado da cultura enquanto novos saberes capazes de transformação, e isso não pode ser realizado com objetos.

Dessa forma, o corpo não é tomado como um objeto no espaço e no tempo, ou então em movimento, definido exclusivamente como um conjunto de partes; pelo contrário, é visto como um modo de unidade que não se resigna a leis externas, conforme a síntese corporal proposta por Merleau-Ponty. Essa síntese do corpo permite perceber e reconhecer aquilo que o corpo e os objetos guardam ocultos, dado que, de acordo com o pensamento merleaupontyano, as partes do corpo não se reúnem uma a uma, mas são todas feitas de uma vez só, constituindo o corpopróprio. Essa unidade do corpo-próprio pode tornar possível a compreensão das bases fenomenológicas da educação a partir da noção de logos estético, tal como Merleau-Ponty a compreendeu, e, dessa forma, no próximo capítulo iremos tratar com mais atenção da questão de como a experiência estética pode ser o momento de nascimento de um tipo de conhecimento pré-reflexivo do corpo ligado às experiências sensíveis e táteis.

Merleau-Ponty, com a pretensão de revisar a atividade perceptiva, introduz uma noção de filosofia direcionada à experiência questionando o Ser além das dicotomias exterior e interior, tal qual vimos nos capítulos anteriores. Para isso, ele refuta o entendimento fragmentado da experiência e a examina em seu caráter estético, recorrendo às manifestações artísticas, como a literatura ou pintura, por exemplo. $\mathrm{O}$ autor infere que, por intermédio dessas obras, nas quais existe a relação com o Ser, impõe-se a investigação ontológica. Já o Ser pressupõe a nossa criação, possibilitando que nossa experiência seja extraída. Dessa forma, a comunhão entre arte e filosofia proporcionará aquele momento em que o Ser poderá vir a ser, pois segundo Chauí (2002, p. 152) em grande parte, o mundo é desprezado por nós que continuamos mantendo uma conduta utilitária e baseada na prática. Foram necessários muitos anos, cultura e esforço para colocá-lo à mostra, e, na modernidade, o valor do pensamento e da arte (...) é o de nos levar a reaver esse mundo em que existimos.

\section{Merleau-Ponty: atividade perceptiva e educação}

Merleau-Ponty sugere uma ontologia diferente da clássica: para determinar uma relação privilegiada entre filosofia e arte, ele propõe desvendar o solo pré-reflexivo composto pela relação entre sujeito e objeto, racional e sensível, visível e invisível, o que acaba por redesenhar o estatuto da arte no processo de conhecimento. Consideramos que essa abordagem, na medida em que pressupõe uma relação sujeito-objeto, adentra em um plano de presença, evidenciando uma noção de educação fundada no mundo sensível de nossa experiência sem prender-se ao senso comum, que entende o sensível como natural e imediato. Em vista disso, objetivamos introduzir a arte em um projeto educacional embasado em uma concepção de experiência perceptiva e que derive da interação entre linguagem e arte.

A tradição filosófica moderna e cartesiana disseminou a chamada filosofia da consciência, que define o corpo como o exterior e a alma como o interior. Como consequência, nesse

ROSA, Mauricio Bueno da. Compreendendo a noção de experiência corporal em Merleau-Ponty: contribuições para a educação. Griot : Revista de Filosofia, Amargosa - BA, v.20, n.2, p.347-359, junho, 2020. 
momento, a existência era observada unicamente conforme esses dois sentidos, como consciência ou, ainda, como coisa.

O autor, diferente do que é pregado pela visão tradicional, compreende o sujeito como consciência encarnada em um corpo, e não como puramente reflexiva. Dessa forma, MerleauPonty afirma (C, p. 9) que:

[...] em grande parte, o mundo é desprezado por nós que continuamos mantendo uma conduta utilitária e baseada na prática. Foram necessários muitos anos, cultura e esforço para colocá-lo à mostra, e, na modernidade, o valor do pensamento e da arte [...] é o de nos levar a reaver esse mundo em que existimos, mas que somos levados sempre a olvidar.

Portanto, é só por meio da arte que conseguimos redescobrir esse lugar que, ao mesmo tempo, tendemos a sempre esquecer. Merleau-Ponty (C, p. 10) ainda complementa dizendo que o desenvolvimento do saber não significou o esquecimento daquilo que nos transmitem os sentidos quando ingenuamente solicitados, e que não possuem, em um quadro real do mundo, um lugar. Assumir que a arte é fundamental para acessarmos esse mundo omitido não significa retirar da ciência a sua importância como instrumento técnico ou como opção de verdade e rigor, mas permite não entendê-la como única fornecedora de questões válidas, visto que, no entender de Merleau-Ponty, a ciência sempre foi uma área em que é fundamental aprender sobre a rigorosidade das pesquisas e verificação, bem como sobre a crítica de si mesmo e de seus próprios preconceitos.

Para adentrar nessa questão, Merleau-Ponty procura entender o campo de significações sensíveis que estabelecem a união entre as coisas e nossas experiências por meio da linguagem e da estética. Como exemplo, podemos citar a pintura, que, conforme explica o próprio autor ( $\mathrm{OE}$, p. 17):

[...] o universo do artista pictórico é exclusivamente visível, um universo quase absurdo, uma vez que é pleno sendo, contudo, incompleto. A sua arte desperta, leva a sua visão mesma ao ápice, que nada mais é que o delírio, isso porque ver é possuir estando longe, e a arte pictórica amplia essa estranha posse a todas as características do ser, que deve, de alguma forma, manifestar-se visivelmente para nela entrar (...) a pintura atribui vida perceptível aos olhos ao que a visão descrente acredita ser invisível, faz com que, para possuir a voluminosidade do mundo, não necessitemos de sentido muscular. Tal visão permite acessar uma textura do ser, onde os sinais sensoriais discretos são somente as cesuras ou as pontuações, trata-se de uma textura em que o olho se abriga tal qual o homem em sua moradia.

Contudo, cabe aqui a tese levantada por Carbone, em La Visibilité de L'Invisible: Merleau-Ponty entre Cézanne et Proust (2001, p. 28, tradução nossa), onde ele observa que "a pintura faz surgir o espetáculo do mundo, as significações que se mantém por trás das aparências e do sentido habitual do mundo trazendo à tona novas significações".

Carbone ainda enfatiza que a pintura não é apenas a materialização de uma ideia através da cor, pois não estamos apenas contemplando uma das múltiplas respostas que a arte dá à sua visão de mundo; ela é uma linguagem entre outras cuja realização exige um estágio anterior à sua própria existência, que começa configurando esse contato de um instante que o artista tem do mundo. 
Além da pintura, há outras formas artísticas e sua significação, que são produzidas na interação de um composto de fatores perceptivos. $O$ espaço de passagem dessa relação é o corpo do musicista, que dá existência à música e permite que o restante também exista por ela. Podemos exemplificar essa passagem afirmando que, estando inteiramente ao dispor da música, o organista alcança justamente as teclas e os pedais que vão realizá-la. Ora, o corpo é eminentemente um espaço expressivo. Eu quero pegar um objeto e, em um ponto do espaço no qual eu não pensava, essa potência de precisão que é a minha mão já se levanta em direção ao objeto. Movo minhas pernas não enquanto elas estão no espaço a oitenta centímetros de minha cabeça, mas enquanto sua potência ambulatória prolonga para baixo a minha intenção motora (PhP, p. 201). O fato de a significação musical resultar da soma de gestos que produzem sons, advindos de um instrumentalista que, por estar totalmente ao dispor da canção, alcança, especificamente, os equipamentos que vão originá-la, comprova que o corpo é um meio expressivo.

Mas nosso corpo não é apenas um espaço expressivo entre todos os outros. Este é apenas o corpo constituído. Ele é a origem de todos os outros, o próprio movimento de expressão, aquilo que projeta as significações no exterior dando-lhes um lugar, aquilo que faz com que elas comecem a existir como coisas, sob nossas mãos, sob nossos olhos. (PhP, p. 201)

Essa expressão não se restringe, portanto, a um sistema padronizado de significados, sendo que as formas de linguagem têm uma dimensão expressiva e instituidora de sentidos que estabelecem a relação dos seres humanos entre si e com o restante do mundo. Dessa forma, a arte expressa na pintura reflete aspectos da existência que a filosofia precisa desenredar em seus movimentos. Essa área do saber que esclarece a incógnita do visível e do invisível faz o completo oposto da ideia de um "sobrevoo", pois, como elucida Merleau-Ponty (S, p. 22).

Desveladora dessa antítese do invisível e do visível, a filosofia é exatamente o oposto de uma análise que fica na superfície. Ela penetra na direção, na história, no tempo, no sensível de suas conexões, não as suplanta exclusivamente por suas forças, suplanta-as somente em seus sentidos.

Avançando na nossa interpretação em relação à expressão perceptiva, temos em vista que as produções artísticas manifestam um modo de existir próprio de quem habita o mundo e o enxerga por dentro, obtendo, como resultado, algo que não se configura como uma imitação.

Com base na apreensão do movimento da vida, a arte possibilita outra leitura do mundo e também da própria formação humana. Relacionar organicamente arte e pensamento, e linguagens distintas, faz conceber perspectivas inovadoras para se entender a realidade. Discorrer sobre a ligação entre filosofia e arte significa realçar a crítica idealizada por MerleauPonty ao pensamento científico, sustentáculo da ciência moderna, e ao idealismo, determinante da filosofia moderna: quer seja porque a filosofia tradicional, para falar da essência de algo, precisa abstrair de sua existência, ou porque a ciência, objetivando definir um objeto, limita a realidade a uma extensão sem qualidades. Filosofia e arte aproximam-se, na concepção de Merleau-Ponty, uma vez que têm em comum, como fundamento, a experiência originária do mundo, dimensão espontânea e natural onde situam-se o pintor e o filósofo. Arte e filosofia, pintura e linguagem aproximam-se como criações, ao expressarem um contato com o ser, de um ser que fala em nós existencialmente, antes de falar conceitualmente, mas que só é na expressão,

ROSA, Mauricio Bueno da. Compreendendo a noção de experiência corporal em Merleau-Ponty: contribuições para a educação. Griot : Revista de Filosofia, Amargosa - BA, v.20, n.2, p.347-359, junho, 2020. 
em presença.

A relação entre filosofia e arte se faz fundamental para pensar a formação humana e a educação nos termos que estamos pesquisando aqui, pois trata-se da própria fundamentação do conhecimento, a partir de uma atitude de experiência perceptiva com o mundo no qual estamos inseridos. Essa relação sensorial se define pela própria expressão corporal por meio da construção de significados, que a partir da experiência estética, tornam possível um diálogo com o mundo e também na forma da intersubjetividade. Se falamos aqui de um conhecimento que é anterior a uma intelecção voluntária, Merleau-Ponty compreende que essa apropriação do conhecimento por meio da expressão estética se faz por toda e qualquer pessoa, tornando a educação acessível a todos, mesmo que com limitações cognitivas. Dessa forma, a criança compreende o mundo antes de abordá-lo sistematicamente, e é isso que nos interessa no processo da formação humana.

\footnotetext{
Na obra de arte, o que é insubstituível, o que a faz mais que um objeto de deleite é um componente do espírito, analogamente presente em toda política, quando positiva, e filosofia. Além disso, mais do que conter ideais, ou originar ideias, ela nos oferece representações cujo sentido nunca acabaremos de desenvolver, e, em razão de se colocar e de nos colocar em um mundo sem saída, mostra-nos a ver e, por fim, faz-nos pensar de forma única, como nenhuma obra analítica pode fazer, pois que a análise conhece no objeto somente o que depositamos nele. (S, p. 81)
}

$\mathrm{O}$ autor retoma o logos e inicia a discussão sobre o significado da arte pictórica em sua dimensão metafísica na sua obra $O$ Olho e o espírito, dessa vez com uma visão aberta ao mundo, com a pretensão de exaltar o enigma da visibilidade. Em geral, as obras de arte não evocam uma essência, mas desnudam o mundo em minúcias despercebidas no dia a dia; por isso dizemos que o pintor nos mostra o que não somos capazes de enxergar, já que é o corpo que:

[...] vê tudo, pode ainda se ver e então distinguir no que vê o lado de lá do seu poder de vidência. Ele se percebe vidente, ele se toca tocante, é sensível e visível para si. Consiste em um si, não porque é invisível, como o pensamento, que apenas pensa seja lá o que foi transformando-o, constituindo-o, assimilando-o em pensamento, mas é um si por desorganização, por narcisismo, por indissociabilidade daquele que toca ao que ele toca, daquele que olha ao que ele olha, do sensível ao sentido. Trata-se de um si que é, portanto, tomado entre coisas, que possui um passado e um futuro, um verso e um reverso. (OE, p. 19)

Merleau-Ponty celebra o mistério da visibilidade porque o invisível não é algo que está diverso ou oculto, é somente aquilo que não chegamos a visualizar. Nesse caso, a pintura confere uma visibilidade existente àquelas coisas que a observação comum considera invisível. É importante entender que, ao fazer visível o que não conseguimos enxergar ordinariamente, a obra de arte não repete as coisas nem o mundo, bem como não omite algo para além de si. $O$ artista apenas estimula o nosso imaginário e seu constante aprendizado do artista com o mundo e com os demais, junto com a experiência de ver, definem o dom do visível. Essa experiência de delírio, que é a própria visão, como já descrevemos anteriormente, traz à tona o invisível. Nesse processo, cria-se um estilo, um significado e uma presença reconhecida pelo observador em traços, sombras, escolhas de cores e combinação de luzes que, juntas, delimitam a profundidade e as formas. Até quando se debruçam sobre objetos reais, os artistas não representam o próprio objeto, pois: 
[...] Ainda que trabalhando sobre objetos existentes, seu propósito nunca foi invocar o objeto em si, mas criar sobre a tela um espetáculo que se complete. A diferenciação feita frequentemente entre o método do pintor o tema da obra é ilegítima, pois que, para o logos estético, o tema está no modo mediante o qual o artista constitui na tela o maço de cigarros, o cachimbo ou a uva. (S, p. 59)

Segundo Merleau-Ponty, o artista que melhor demonstrou a interação entre filosofia e arte foi Cézanne. Merleau-Ponty (S, p. 88) afirma que Cézanne não recusou aparência dos rostos e dos objetos, ele tinha como intenção apenas assimilá-la quando ela aflorasse. Retratar um rosto enquanto objeto não é privá-lo de seu pensamento. No entanto, tal interpretação não deve constituir um pensamento isolado da visão. Nas obras de Cézanne, identificam-se os elementos estéticos, porém, não como dimensões, e sim como relações que propiciam a criação de uma obra pictórica, na qual se notam tentativas constantes de decifrar o enigma da visibilidade. Se a intenção do artista for expressar o mundo, é necessário que a combinação das cores desvele o indivisível; cada pincelada deve ser pensada para expressar o real, pelo contrário irá apenas aludir a coisas, sem enquadrá-las.

Caso o pintor deseje expressar o mundo, é necessário que a cominação das cores contenha em si mesma esse Todo impossível de ser dividido. Não fazendo isso, a pintura será uma mera insinuação aos objetos e não revelará na completude inatingível, na presença, na unidade magnífica que é, para todos os homens, a descrição da realidade. É daí que surge a necessidade de cada pincelada corresponder a inúmeras condições, esse o motivo das meditações de Cézanne antes da execução de seu trabalho. Conforme diz Bernard, a pintura deve comportar o estilo, o desenho, o caráter, o plano, o objeto, a luz, o art. Para expressar aquilo que existe, requer-se um trabalho sem fim. (OE, p. 87)

Por esse motivo, não podemos atribuir à obra artística uma significação livre, posto que ela é refém de todos os pormenores que ela manifesta e, do mesmo modo, temos que a percepção é única, não podendo ser analisada e nem definida. Trata-se, portanto, de interpretar e perceber a pintura conforme as "indicações silenciosas" dos elementos que formam sua composição, até que todos eles, sem o esforço do raciocínio e do discurso, se organizem a ponto de entendermos que nenhuma escolha foi arbitrária, mesmo que não compreendamos ou não saibamos explicar os motivos. ${ }^{6}$

Merleau-Ponty nos esclarece essa questão afirmando que:

O pintor a transforma exatamente em objeto visível, que, sem sua atuação, mantém-se ocluso da vida, distanciado das consciências. A única emoção possível para um pintor como esse é a sensação de estranheza, e a existência, sempre em recomeço, é seu único lirismo. (OE, p, 89)

A pintura dá nova significação ao corpo e ao espaço, tornando-o visível sem recorrer à imitação, e ampliando a percepção e a experiência sensível. De modo geral, os trabalhos artísticos exteriorizam o mundo perceptivo em todos os seus detalhes e nos apontam a fisionomia do mundo, bem como a nossa, que nasce no movimento da vida. Na elaboração de

\footnotetext{
${ }^{6}$ Carbone (2001, p. 32) observa que: "Cézanne concebe a maneira como a arte deveria exprimir o mundo, esquiva-se de aplicar à sua pintura a separação entre o sensível e o inteligível, pois o visível não se limita apenas ao que aparece na superfície da tela, pois há um horizonte de coisas não vistas ou mesmo não visíveis" (tradução nossa).
}

ROSA, Mauricio Bueno da. Compreendendo a noção de experiência corporal em Merleau-Ponty: contribuições para a educação. Griot: Revista de Filosofia, Amargosa - BA, v.20, n.2, p.347-359, junho, 2020. 
uma obra, cada particularidade deve atender a inúmeras condições sendo que essa tarefa infinita e sempre reiniciada é a experiência que a filosofia pode aprender com a arte. Dessa forma, a educação pode reaprender com o campo artístico que somos no mundo, ele é a nossa morada e, em seu interior, devemos produzir nossos pensamentos intrincados à ação. Pode, também, redescobrir como observar o mundo, como vencer os dualismos e aprender a compartilhar o mistério da visibilidade, pois como afirma Merleau-Ponty:

A visão consiste em um tipo de pensamento que decodifica especificamente os signos presentes no corpo. A semelhança não é sua motivação, mas é consequente da percepção. Com razão mais forte, a representação mental, a vidência que torna presente para nós o que é ausente, de forma alguma é como uma porta para o interior do ser. É um pensamento sustentado por sinais do corpo, não suficientes, aos quais, mas do que significam, ela faz dizer. (OE, p. 22)

A partir desse contexto da pintura, pensamos a educação e sua relação com o logos estético, já que Merleau-Ponty aborda esse tema em outros contextos. Dessa maneira, é fundamental citarmos os escritos do filósofo francês sobre Leonardo da Vinci e sua relação com a produção estética de Cézanne. ${ }^{7}$

Esse posicionamento merleaupontyano acerca da arte abrange uma noção de educação na qual é preciso desvanecer-se da educação primeira e supõe que o artista deve se esforçar para enxergar o que é visível e, principalmente, o que não é. Apesar de seguir um caminho contrário ao dos filósofos, da Vinci reunia arte e filosofia em suas realizações e entendia a pintura enquanto um instrumento filosófico. Para ele, a obra pictórica assumia essa função ao passo que manifesta as exigências profundas, a necessidade de fatos, a constância da sede por causas e a curiosidade generalizada que acompanham a filosofia.

A filosofia do pintor em questão evidencia-se na forma como o pensamento é restaurado pelas experiências da vida e pela análise do mundo. Ela e a arte se aproximam na qualidade de criação. Assim como o real é interrogado pela arte, a filosofia também precisa absorver vida e pensamento e os dois campos devem apontar a estrada da educação. Esta última precisa ser efetivada pela experiência perceptiva e partir do movimento da vida e da experiência para que possa se designar conhecimento. Termos o que transmitir e apreender faz com que as atividades artísticas e filosóficas sejam interessantes: o que vale é o movimento, os vários aspectos do saber e da vida que se cortam, por isso não existe um ponto fixo, um final feliz, ou um porto.

Por expor a nossa condição no mundo em uma contínua tentativa de desvendar o enigma da visibilidade de um ser encarnado e introduzido em um contexto espaciotemporal específico, a pintura se caracteriza como um meio privilegiado de expressão. A linguagem é o nosso instrumento para construir significados e estabelecer nossa relação com o mundo, já a arte pictórica realça nossa forma de existir como um corpo situado. $O$ mundo da experiência perceptiva nos esclarece que as coisas são como aparentam e que o conhecimento se fortifica na

\footnotetext{
${ }^{7}$ Merleau-Ponty (OE, p. 90) afirma que o pintor Leonardo da Vinci assumiu como limite o rigor incansável, as artes poéticas clássicas tomam a obra como complexa. Igualmente os de Mallarmé ou de Balzac, os problemas enfrentados por Cézanne são de outro caráter. Conforme as Delacroix, Balzac idealiza um artista que deseja expressar a vida apenas por meio das cores e mantém sua obra-prima em segredo. Em comum, nas obras dos dois artistas encontramos a aliança entre filosofia e arte, assim como ambos tinham a liberdade como propósito para a ação, apesar de não poder ser descrita como uma força abstrata que sobrepusesse seus impactos aos fatos da vida ou medisse seus desenvolvimentos. Para Leonardo Da Vinci, ciência e arte, sobretudo a pintura, estavam diretamente relacionadas, entendimento que derivava de sua concepção de conhecimento e experiência.
}

ROSA, Mauricio Bueno da. Compreendendo a noção de experiência corporal em Merleau-Ponty: contribuições para a educação. Griot : Revista de Filosofia, Amargosa-BA, v.20, n.2, p.347-359, junho, 2020. 
experiência perceptiva, que carrega o movimento, a contingência, o inacabado e a ambiguidade como características.

\section{Considerações finais}

Nessa trilha, confirmamos que a arte, tal como pensada por Merleau-Ponty, se aproxima da filosofia e da educação, pois é impossível filosofar renegando a condição humana, posto que essa ação pretende desvelar o sentido original do ser. Portanto, ao invés de negá-la, é necessário assumi-la. Ao final, debruçados nas pesquisas de Merleau-Ponty, compreendemos a árdua tarefa que é defrontar o mistério da sensibilidade na esfera da educação, admitir a arte enquanto tarefa infinita e a filosofia como uma reflexão inacabada, além de identificar as ambiguidades e contradições que permeiam nossas vidas. Realizar esse momento em sala de aula, no qual podem se demonstrar a historicidade e a efemeridade das verdades, questionar cada uma delas e assumir, dessa forma, a função infindável do pensamento e sempre recomeçada da ação é a difícil missão da educação. Entretanto, uma renovação nesse quesito implicaria na transformação no trato da própria filosofia que, apesar de sua abordagem universal, ainda precisa levar em consideração seu pertencimento a um contexto histórico no qual constituímos nossas vidas coletiva e individual. O que nos torna, concomitantemente, diferentes e iguais e nos permite optar por nossos caminhos ao mesmo tempo em que nos impõe condições, resultando em um destino comum, é o movimento da vida. É uma perspectiva filosófica que demanda novas ações educativas, nas quais a arte é reconhecida como dimensão formativa. 


\section{Referências}

CARBOnE, Mauro. La Chair des images: Merleau-Ponty entre peinture et cinéma. Paris: Vrin, Matière étrangère, 2011.

CARBONE, Mauro. La Visibilité de L'Invisible: Merleau-Ponty entre Cézanne et Proust. Alemanha: Europaea Memoria, 2001. Disponível em: https://www.persee.fr/docAsPDF/phlou_0035-

3841_2002_num_100_4_7456_t1_0841_0000_2.pdf. Acesso em: 07 de janeiro de 2018.

CARBONE, Mauro. Il Sensibile e l'Eccedente: mondo estetico, arte, pensiero. Itália: Guerini Studio, 1996.

CHAUÍ, M. Experiência do pensamento/ Ensaios sobre a obra de Merleau-Ponty. São Paulo: Martins Fontes, 2002.

CHAUÍ, M. Da Realidade sem mistérios ao mistério do mundo (Espinosa, Voltaire, MerleauPonty). São Paulo: Brasiliense, 1981.

Vozes, 1979.

GILMORE, J. Between Philosophy and Art. In: The Cambridge Companion to Merleau-Ponty. Cambridge: Cambridge University Press, 2006. Disponível em: https://www.partiallyexaminedlife.com/?get_group_doc=26/1357000345-

CambridgeCompaniontoMerleau-Ponty.pdf. Acesso em: 07 de janeiro de 2018.

GRONDIN, Jean. Introdução à Hermenêutica filosófica. São Leopoldo: UNISINOS, 1999.

HACKLIN, Saara. Divergencies of Perception: The Possibilities of Merleau-Pontian Phenomenology. In: Analyses of Contemporary Art. Helsinki, 2012. Disponível em: https://helda.helsinki.fi/bitstream/handle/10138/29433/divergen.pdf. Acesso em: 07 de janeiro de 2018.

LÉTOURneAU, Patrice. Le Phénomène de l'Expression Artistique - Une reconstruction à partir des theses de Maurice Merleau-Ponty. Canadá: Éditions Nota bene, 2005.

MACHADO, Marina. Merleau-Ponty e a Educação. Belo Horizonte: Autêntica, 2010.

MADISON. G. B. Le Postulat d'objectivité dans la science et la philosophie du sujet. In: Revue Philosophiques. Volume 1, Numéro 1, avril, 1974, p. 107-139. Disponível em: https://www.erudit.org/fr/revues/philoso/1974-v1-n1-philoso1318/203005ar/. Acesso em 07 de janeiro de 2018.

MERCURY, Jean-Yves. La Chair du Visible - Paul Cézanne et Maurice Merleau-Ponty. Paris: L'Harmattan, 2005.

MERLEAU-PONTY, Maurice. Causeries - 1948. Paris: Seuil, 2002.

MERLEAU-PONTY, Maurice. L'oeil et l'esprit. Paris: Gallimard Folioplus, 2006.

MERLEAU-PONTY, Maurice. La phénoménologie de la perception. Paris:

Gallimard, 2014. PM La prose du monde. Paris: Gallimard,2004.

MERLEAU-PONTY, Maurice. Signes. Paris: Gallimard, 2001.

MERLEAU-PONTY, Maurice. Psycologie et pédagogiedel'enfant:coursdeSorbonne19491952.Paris: Verdier, 2001.

MOUTINHO, Luiz D. S. Razão e experiência: ensaio sobre Merleau-Ponty. Rio de Janeiro: Editora Unesp, 2006.

MOURA, Carlos A. R. de. Racionalidade e crise - estudos de história da filosofia moderna e contemporânea. São Paulo: Discurso/EDUFPR, 2001.

MOURA, Carlos A. R. de. Intencionalidade e Existência: Husserl e Merleau-Ponty. Salvador,

ROSA, Mauricio Bueno da. Compreendendo a noção de experiência corporal em Merleau-Ponty: contribuições para a educação. Griot : Revista de Filosofia, Amargosa - BA, v.20, n.2, p.347-359, junho, 2020. 
2011.

MOURA, Carlos A. R. de. Crítica da razão na fenomenologia. São Paulo: Edusp/Nova Stella, 1989.

MOURA, Carlos A. R. de. A cera e o abelhudo - expressão e percepção em Merleau-Ponty. In: Racionalidade e crise - estudos de história da filosofia moderna e contemporânea. São Paulo: Discurso/EDUFPR, 2001.

MÉNASÉ. Penser avec Merleau-Ponty: un processus génétique. In: Genesis. Número 22, 2003. Philosophie. Disponível em: https://www.persee.fr/doc/item_1167-101_2003_num_22_1_1280. Acesso em 07 de janeiro de 2018.

MULLER, Marcos José. Merleau-Ponty acerca da expressão. Porto Alegre: EDIPUCRS, 2001.

SLATMAN, Jenny. L'expression au-delà de la représentation: sur l'aisthêsis et l'esthétique chez Merleau-Ponty. Leuven/Paris: Peeters, 2003.

WAYNE J. F. Merleau-Ponty and the relation between Logos Prophorikos and the Logos Endiathetos. In: Logos of Phenomenology and Phenomenology of the Logos. Phenomenology as the Critique of Reason in Contemporary Criticism and Interpretation. Hanover: Springer, 2005. Disponivel em: https://pt.scribd.com/document/371700484/Analecta-Husserliana-LXXXXIlogos-of-phenomenology-and-phenomenology-of-the-logos-pdf. Acesso em 07 de janeiro de 2018.

Autor(a) para correspondência: Mauricio Bueno da Rosa, Rua Vitor Meirelles, Santa Rita, Brusque - SC, Brasil. mauriciobueno7@hotmail.com 